ted by order of the government, London, reprinted for J. Sewell, Cornhill \& J. Debrett, Piccadilly).

Las Siete Partidas del Sabio Rey Don Alfonso el Nono nuevamente glosadas por el licenciado Gregorio López (Salamanca, Andrea de Portonariis, 1555).

Loiseleur Deslongchamps, Auguste Louis Armand (1833): Lois de Manou, comprenant les institutions religieuses et civiles des Indiens (Paris, Imp. de Crapelet).

Oliver, Bienvenido (1876-1881): Historia del Derecho en Cataluña, Mallorca y Valencia. Código de las Costumbres de Tortosa, 4 Tomos (Madrid, Imprenta de Miguel Ginesta).

Ordonnance touchant la marine du Mois d’Aoút (1681).

Pardessus, Jean Marie (1828-1848): Collection de lois maritimes antérieures au XVIII siècle, 6 Tomos (Paris, L'Imprimerie Royale). 


\title{
PROTEGER LO ORIGINAL: CONSIDERACIONES EN TORNO A LA PROTECCIÓN DE LA PROPIEDAD INTELECTUAL E INDUSTRIAL DURANTE LA PRIMERA ETAPA DE LA LEGISLACIÓN PATRIA
}

\author{
PROTECTING THE ORIGINAL: CONSIDERATIONS ON \\ INTELLECTUAL PROPERTY PROTECTION. FIRST STAGE IN THE \\ CHILEAN NATIONAL LAW
}

\section{JaVier Infante Martin ${ }^{*}$}

RESUMEN: El Derecho de la Propiedad Intelectual, en su sentido amplio, fue objeto de interés por parte del legislador desde los comienzos de la vida política independiente. El fomento a las artes, la cultura, la industria y el desarrollo, fue de la mano de una protección certera sobre la propiedad que autores e inventores tenían respecto a sus creaciones. El presente artículo aborda el desarrollo, planteamiento, discusión y fuentes de aquellos primeros cuerpos legislativos, que hicieron de Chile uno de los primeros países iberoamericanos en regular detalladamente la materia.

Palabras clave: Propiedad intelectual, legislación patria, propiedad literaria, privilegios industriales, patentes.

ABSTRACT: Intellectual Property Law, in its broad sense, was of primary interest to the Chilean law makers since the beginnings of independent political life. The promotion of arts, culture, industry and development, advanced in parallel with a secure protection on the property of authors and inventors regarding their respective creations. This article analyze the development, different approaches, discussions and sources of those first laws regarding Intellectual Property, which made Chile one of the first former colonies who regulated that area in detail.

Keywords: Intellectual property, first Chilean legislation, copyright law, industrial privileges, patent law.

\section{INTRODUCCIÓN}

El estudio de la historia de la propiedad intelectual en Chile durante el Siglo XIX no ha sido una preocupación de primer orden para los historiadores del Derecho. Escasas menciones existen sobre el punto, el que ha sido abordado a propósito de los antecedentes que generalmente se presentan en investigaciones de Derecho vigente. Así lo ha tratado Pablo Ruiz-Tagle, quien ha dedicado un capítulo de su obra al tema bajo el título Ensayo

\footnotetext{
Doctor en Derecho por la Universidad de Navarra, Profesor Asociado de la Facultad de Derecho, Pontificia Universidad Católica de Chile, y Profesor Afiliado al Centro de Estudios Internacionales, Pontificia Universidad Católica de Chile. Dirección postal: Alameda 340, Facultad de Derecho, $4^{\text {to }}$ piso, Santiago de Chile. Dirección electrónica: jfinfante@uc.cl. Este artículo forma parte del proyecto Fondecyt regular número 1190486.
} 
Histórico General del caso chilenoํ. En un trabajo más reciente, Elisa Walker ha dedicado asimismo una referencia a los antecedentes constitucionales de dicha protección durante el Siglo XIX ${ }^{2}$. Santiago Larraguibel Zavala, en su Tratado sobre la Propiedad Industrial ${ }^{3}$, no hace mención alguna a los antecedentes legislativos chilenos, mientras que Vladimir García-Huidobro dedicó tan solo un corto párrafó . Otros estudios se han enfocado en la publicación de las patentes concedidas, pero no en el estudio de la normativa que las afectaba ${ }^{5}$. Acaso el estudio más acabado sobre la historia de la Propiedad Intelectual -en un sentido restringido- se encuentre en el trabajo de Camilo Mirosevic, titulado "Origen y evolución del Derecho de Autor, con especial referencia al Derecho Chileno", trabajo que no obstante se enfoca exclusivamente en el Derecho de Autor, presentando detalladamente los antecedentes históricos de dicho fenómeno, pero sin desarrollar latamente la historia de la legislación chilena.

Se aprecia pues, un vacío en el estudio de la formación jurídica nacional, que puede resultar acaso de interés para quienes dediquen su estudio al amplio campo del Derecho de la Propiedad Intelectual.

En consecuencia, el presente trabajo enfocará su estudio en el origen de las primeras normas de propiedad intelectual aplicadas en nuestro país -heredadas del Derecho español-, al igual que en las primeras disposiciones chilenas sobre la materia. Dado que el desarrollo intelectual e industrial de la primera mitad del Siglo XIX chileno no fue precisamente descollante, y la introducción de inventos provenientes del extranjero tuvo su aplicación principalmente en los campos hasta entonces desarrollados en la economía nacional -principalmente minería y agricultura-, resulta posible tratar en conjunto el desarrollo del Derecho de la Propiedad Intelectual en un sentido amplio, esto es, Derechos de Autor y Propiedad Industrial. Sin embargo, no se estudiarán -a propósito de la Propiedad Industrial- los primeros antecedentes de legislación marcaria ${ }^{6}$, que quedarán para otras investigaciones.

El objeto del presente trabajo es presentar un estudio con antecedentes inéditos sobre el origen y discusión de las primeras normas de Propiedad Intelectual en Chile, dejando el análisis de su aplicación en tribunales para otros estudios. No obstante, se ofrecerá un ejemplo de aplicación judicial de la ley de Derechos de Autor de 1834, que ilustra ciertos inconvenientes en la aplicación e interpretación de la ley, como se verá, en desmedro del autor litigante.

\footnotetext{
1 Ruiz-Tagle (2001) pp. 115-208.

2 WaLKer (2014) p. 48.

3 Larraguibel (1995). Sin embargo, en otra obra dedica cerca de 5 páginas al estudio de estos antecedentes. LARRAGUibel (1987) pp. 7-11.

4 García-Huidobro (1992) p. 33.

5 Caselli (Ed.) (2010); Montero (1913).

${ }^{6}$ La primera legislación marcaria en Chile es del 12 de noviembre de 1874. Larraguibel (1987) p. 11.
} 


\section{EL DERECHO DE AUTOR EN CHILE DESDE LA COLONIA HASTA LA CONSTITUCIÓN DE 1833}

La propiedad intelectual, en un sentido amplio, es aquella que tiene por objeto los productos del ingenio. Desde muy temprano, dicha materia ha recibido protección por parte del Derecho. Ya en el Digesto, Justiniano reprodujo la Lex Cornelia de falsis, relativa a ciertas falsificaciones ${ }^{7}$. Como señala Berkovitz ${ }^{8}$, la legislación española reconoció desde muy temprano la necesidad de contar con cierto grado de protección respecto a las creaciones de sus autores, e indica como primer antecedente directamente relacionado con dicha protección la Real Orden dictada por Carlos III el año 1764 más tarde incorporada en la Novísima Recopilación de 1805. Dicha norma señalaba que “...los privilegios concedidos a sus autores no se extingan por su muerte, sino que pasen a sus herederos, como no sean Comunidades o Manos muertas: y que estos herederos se les continúe el privilegio mientras le solicitan, por la atención que merecen aquellos literatos, que después de haber ilustrado a su Patria, no dejan más patrimonio a sus familias que el honrado caudal de sus propias obras, y el estímulo de imitar su buen ejemplo"'. Como se puede apreciar, la protección entregada al autor valía durante su vida, y se extendía a sus herederos. No obstante, la norma no explicitaba el plazo de protección que se entregaba a los herederos del autor, así como el alcance de la misma. Es por ello que esta ley sería más tarde complementada con otra Real Orden de 1778, que desarrollaba de manera precisa el alcance de la protección en torno a los derechos de autor. En esa oportunidad, Carlos III hacía extensiva la protección de los derechos de autor a determinadas entidades -Personas Jurídicas- en cuyo seno se generaba el conocimiento, con la salvedad de extinguirse dicha protección al momento del fallecimiento del autor de la obra, salvo en los casos, y he aquí una novedad importante, en que la nueva publicación fuese acompañada de elementos nuevos, en cuyo caso dicho carácter original, hacía que a las personas o entidades "se las debe reputar, no como meros editores, sino como coautores de las obras que han ilustrado". Dicho de otro modo, Carlos III logró distinguir la creación original de la alteración que a posteriori se hiciera sobre la misma ${ }^{10}$. Asimismo, se señalaba que si los herederos no hacían reclamación de los derechos transmitidos dentro del plazo de un año contado desde la muerte del autor, esta pasaba a disposición del Gobierno, el que debía promover su conocimiento, sin que por ello la obra pasara a lo que hoy se denomina patrimonio común.

Si bien es discutible la vigencia que la Novísima Recopilación puede haber tenido en América, no por ello podemos desconocer que la Real Orden recopilada en ella fue dictada como un acto legislativo independiente, en el contexto borbónico. Ello nos lleva a pensar

\footnotetext{
7 BerKemeyer (2009) p. 123.

8 Berkovitz (2012) p. 40; Walker (2014) p. 5.

9 Novísima Recopilación de las Leyes de España ley XXV, Tit. XVI, Libro VIII, en adelante Nov. Rec. Esa política de Carlos III de fomentar la literatura y las luces se vio también reflejada en una Real Orden anterior de 1762 que decía "...y siendo la libertad en todo comercio madre de la abundancia, lo será también en este de los libros...", como justificación a la eliminación de los impuestos sobre estos bienes. El precio debía ser simplemente aquel “...que los autores y libreros quieran poner...”. Nov. Rec. Ley XXIII, Tit, XVI, Libro VIII.

${ }^{10}$ Nov. Rec., Ley XXVI, Tit. XVI, Libro VIII.
} 
que, considerando el ímpetu legalista de los Borbones españoles, así como sus pretensiones centralistas, la Real Orden de 1778 antes mencionada tuvo plena vigencia en América y especialmente en Chile, como se verá más adelante. En consecuencia, el primer antecedente de protección de la propiedad intelectual en nuestro país habría tenido origen precisamente durante el período colonial, legislación que como sabemos, mantuvo su vigencia tras el movimiento de Independencia. Como sea, en lo que a plazos respecta, vemos que la legislación es ambigua, no estableciendo plazos concretos de protección para los herederos tras la muerte del autor, e incluso condicionando dicha protección a la solicitud de los mismos.

En el Derecho Patrio, la situación fue levemente distinta. Si bien la primera ley que expresamente protegía la propiedad intelectual tuvo lugar en 1834, otras normas dan cuenta de cierto grado de reconocimiento que el Estado daba a los autores e inventores. Tal es el caso de las normas relativas al uso de la imprenta, instrumento que permitía precisamente fomentar las luces y la libertad política que justificaba la Independencia y formación republicana. En consecuencia esta materia ha sido tratada de manera preferente desde los primeros momentos de autonomía política, dictándose la primera ley sobre la materia en $1813^{11}$, norma que si bien no hacía mención expresa a ningún tipo de protección, si reconocía el derecho de todos los hombres a publicar sus escritos mientras no riñesen con ciertas limitaciones -como la Fe Católica o la moralidad-. Esta ley fue reconocida y complementada una década más tarde por otra dictada bajo el Gobierno de Ramón Freire. Esa norma complementaria tampoco otorgaba protección alguna a los autores, pero avanzaba un poco más allá que su antecedente, señalando expresamente que autores y editores debían firmar sus obras, para que la autoría fuese conocida $-y$ en consecuencia, la eventual responsabilidad por infracción a la norma- ${ }^{12}$. Del mismo modo enfrentaron el problema los constituyentes de la época. Si bien la propiedad privada fue protegida constitucionalmente en casi todas las normas de rango constitucional anteriores a 1833, ninguna de ellas se hizo cargo de la propiedad intelectual. Sin embargo, desde la Constitución Provisoria de 1818 se reconoce constitucionalmente el derecho de todo hombre para publicar sus ideas ${ }^{13}$.

El primer avance en la materia vino de la mano del Voto Particular de Mariano Egaña, el que señalaba en su artículo 177 que "Todo inventor tendrá la propiedad de sus descubrimientos y de sus producciones. La ley le asegurará un privilegio exclusivo temporal o resarcimiento de la pérdida que tenga, en caso de exigírsele su publicación"14. El antecedente legal que Mariano Egaña consultó para introducir esa indicación, hasta entonces inédita en el constitucionalismo chileno, resulta desconocido, aunque existen fuertes

\footnotetext{
11 Disposiciones relativas a la libertad de la prensa, Decreto de la junta de Gobierno con acuerdo del Senado, de 23 de junio de 1813

12 Artículo 2. Adición a la Ley DE Imprenta (18/6/1823).

13 Ello puede verse en las siguientes normas: Constitución Provisoria de 1818, artículo 11; ConstituCión Política del Estado de 1822, artículo 223; Constitución Política del Estado de Chile de 1823 artículo 262 y Constitución Política de la República de Chile de 1828, artículo 18.

14 Letelier (1887-1908) Tomo XXI, p. 97.
} 
indicios de que su origen se remontaría a la Constitución brasileña de $1824^{15}$. También es necesario agregar que Mariano Egaña debió de haber conocido la obra de Jean Baptiste Say, Tratado de Economía Política, que fue posiblemente traducida por su padre ${ }^{16}$. De ser así, Mariano Egaña habría podido conocer los beneficios que Say reconocía en torno a la protección de los inventores sobre sus inventos ${ }^{17}$. Ahora bien, independientemente de la inspiración de Mariano Egaña para introducir el artículo en cuestión, debemos decir que este no fue particularmente discutido por la Convención, no obstante haber sido cuestionado por el tribuno José Miguel Infante a través de El Valdiviano Federal ${ }^{18}$. Por otra parte, la falta de controversia en torno al artículo propuesto no es sinónimo de un absoluto consenso en su contenido, ya que se puede apreciar en los mismos borradores de Mariano Egaña ciertas dudas respecto al alcance de su propuesta. Es así como en uno de ellos se puede leer como nota complementaria al artículo reproducido más arriba lo siguiente:

"A la expresión de "todo inventor" pudiera añadirse en objetos de utilidad pública, porque si el Erario ha de indemnizar su publicación o comunicación, es preciso que la invención sea de notoria utilidad" ${ }^{\prime \prime}$.

Como se puede apreciar, Egaña tenía ciertos reparos en torno a la naturaleza del alcance de la procedencia de la indemnización en caso de que se obligase a publicar un invento protegido, la que debía proceder únicamente frente a casos de expropiación sobre privilegios de utilidad pública. Infante sería uno de los principales objetores de este tipo de normas que consideraba ambiguas, dada la flexibilidad interpretativa que las normas contenían ${ }^{20}$.

Finalmente, el Constituyente de 1833 reconoció y otorgó por primera vez ${ }^{21}$ protección sobre la propiedad intelectual en su sentido amplio, abarcando tanto la protección

\footnotetext{
15 Según Enrique Brahm, Egaña habría tomado dicho artículo de la Constitución brasileña de 1824 y su artículo $179 \mathrm{~N}^{\circ}$ 26, del cual el artículo del Voto Particular de Egaña pareciera ser una traducción literal. BRAHM (2007) p. 140. Sin embargo, la ausencia de actas de la comisión de reforma a la Constitución de 1828 nos impide conocer una discusión pormenorizada sobre su origen exacto, así como sobre la intención de sus redactores. MiroseVic (2007) p. 65.

16 Archivo Nacional-Fondo Varios, Vol. 796, Elementos de Economía Política sacados del Tratado de Economía Política de Juan Bautista Say (1819). Creemos que este trabajo de traducción y resumen se debe a Juan Egaña.

17 Say dedica un capítulo al Tema. SAY (1804) p. 337.

18 El Valdiviano Federal, Número 66 (21/1/1833). En dicho artículo, Infante observaba la novedad de este artículo en el contexto jurídico chileno, pero desechaba su utilidad por considerarlo inútil e inmoral, al tiempo en que defendía la completa libertad de los inventores: "El sistema de premios, de privilegios exclusivos y otros de este género será mejor no tenga lugar en nuestros Códigos, si se quiere evitar el que se pongan trabas a la industria y el que sea ciertamente un principio de inmoralidad; todo se consigue dejando que el interés individual obre independientemente de las autoridades".

19 Letelier (1887-1908) Tomo XXI, p. 100.

20 "Al leer este capítulo de la reforma constitucional, observamos que en muchos de sus artículos se remite a lo que la ley determina... ¿Cuántas veces la ley no vulnerará en su determinación particular los Derecho individuales que declaró la Constitución?”. El Valdiviano Federal, Número 66 (21/1/1833).

21 Ruiz-Tagle (2001) p. 131.
} 
debida a los autores como a los inventores, al establecer en su artículo 152 que "Todo autor o inventor tendrá la propiedad exclusiva de su descubrimiento, o producción por el tiempo que le concediere la ley; y si esta exigiere su publicación, se dará al inventor la indemnización correspondiente".

La disposición aprobada fue objeto de comentarios por los tratadistas de la constitución, José Victorino Lastarria y Manuel Carrasco Albano. El primero de ellos dedicó casi nueve páginas de su obra La Constitución Política de la República de 1833 comentada al análisis del artículo, mientras que Carrasco Albano dedicó dos páginas, y reprodujo las leyes generales dictadas a partir de la norma constitucional, que mencionaremos a continuación.

De acuerdo a Lastarria, "la propiedad exclusiva que el artículo 152 concede al autor no es contraria a la libertad industrial, sino que la corrobora. En esto la Constitución no hace otra cosa que reconocer el Derecho Natural que el hombre tiene para aplicar su inteligencia y su actividad para apropiarse la materia... como para hacer suyo lo que es una emanación de su pensamiento..."22. La veta liberal del pensamiento de Lastarria queda manifiesta en su apoyo a la protección de esta norma, la que explica detalladamente, justificando la utilidad de la misma no solo desde el punto de vista individual, sino que incluso desde el punto de vista de la utilidad social en la concesión de protección de este tipo. Continúa Lastarria desarrollando las razones que justifican la duración limitada de este tipo de propiedad, las diferencias de trato que deben hacerse entre la propiedad intelectual e industrial -distinguiendo como esenciales a cada una el derecho de reproducción y el uso exclusivo, respectivamente-, entre otras observaciones. Ahora bien, no obstante Lastarria celebra la inclusión de este artículo y la protección que brinda, critica al mismo tiempo la forma en que establece esa misma protección, equiparando a los autores con los inventores.

Además de todo lo dicho, Lastarria abordó el estudio de las leyes especiales dictadas a propósito del artículo 152, es decir, la Ley de Propiedad Literaria de 1834, y la Ley de Privilegios Exclusivos de 1840, comentarios que mencionaremos más adelante a propósito del estudio de dichas leyes.

Manuel Carrasco se explaya de manera más breve que Lastarria, pero no por ello con menos profundidad. Para Carrasco, la consagración de la protección establecida en el artículo 152 de la Constitución obedecía no solo a la necesidad de contar con una legislación equiparable a la comparada sobre la materia, sino que al reconocimiento de un principio cuyo origen se remonta, en opinión del autor, al Derecho Natural y a la conveniencia económica, no solo del autor o inventor, sino de la sociedad toda que se ve beneficiada a través del progreso industrial ${ }^{23}$.

Más allá de los comentarios que los tratadistas hayan realizado sobre esta norma, es en razón de ella que se dictaron dos leyes que desarrollaron el contenido del artículo, estableciendo el alcance de cada una de estas propiedades, quedando de este modo regulados todos los aspectos de la propiedad intelectual en Chile.

\footnotetext{
22 Lastarkia (1856) p. 202.

23 Carrasco Albano (1858) pp. 227 y ss.
} 


\section{LEY DE PROPIEDAD LITERARIA DE 1834}

\section{HistORIA Y DiSCUSIÓN DE LA LEY}

Esta norma fue introducida para su discusión en el Congreso mediante un mensaje del Presidente José Joaquín Prieto en el año $1833^{24}$. En su mensaje al Congreso, el Presidente Prieto comenzaba con las siguientes palabras: "Conciudadanos del Senado y de la Cámara de Diputados: La atención que merecen aquellos literatos que, después de haber ilustrado a su Patria, no dejan más patrimonio a su familia que el honrado caudal de sus propias obras, y el estímulo de imitar su buen ejemplo..."25.

Como se puede apreciar, el mensaje presidencial hace suyas las palabras que en 1764 utilizaba el Rey Carlos III para reconocer protección a los autores. Continúa el mensaje del Proyecto de Ley de Propiedad Literaria haciendo una expresa referencia a los motivos que inducen al Ejecutivo a tratar en dos leyes separadas la protección intelectual - "literaria"- e industrial. El párrafo merece ser reproducido íntegramente: "Los que en todos los pueblos cultos se conceden a los inventores de máquinas o instrumentos que tengan por objeto facilitar las operaciones de la agricultura o de las artes mecánicas, son siempre más limitados que los que se conceden a los escritores. Los de estos ningún perjuicio causan a las naciones, antes bien, protegen la aplicación al estudio y el descubrimiento de nuevas verdades, y aquellos aunque en sumo grado ventajosos pueden arruinar en un momento un ramo general de industria con provecho tan solo del inventor; el gobierno quisiera por tanto, ser tan sobrio para conceder los de esta clase, como franco para declarar aquellos...".

El proyecto presentado por el Gobierno constaba de 15 artículos, y afectaba, según su artículo primero, a los "autores de todo género de escritos o de composiciones de música, de pintura, dibujos, escultura, y en fin, todos aquellos a quienes pertenecen la primera idea en una obra de literatura o bellas letras, tendrán el derecho exclusivo durante su vida, de vender, hacer vender o distribuir en Chile su obras por medio de la imprenta, litografía, grabado, molde o cualquiera otro medio de reproducir o multiplicar las copias". Como se puede apreciar, el artículo abarcaba todo el espectro de creaciones posibles de acuerdo a la técnica de su tiempo, otorgando protección de derechos de autor a cualquier manifestación u obra física o literaria. Asimismo, se entregaba al autor la facultad de vender, hacer vender o distribuir sus obras, sin realizar una distinción expresa entre derechos morales - paternidad de la obra- de derechos patrimoniales. En artículo tercero complementaba esta disposición, al señalar que los autores y sus herederos podían transmitir sus derechos a cualquiera persona.

El artículo 10 del proyecto señalaba que para que dicha protección se hiciese efectiva no era necesario título alguno del gobierno, y tan solo era necesario el depósito de tres ejemplares de la obra en la Biblioteca pública de Santiago, entidad que anunciaría la autoría de la obra depositada. Finalmente, cabe destacar que el artículo 2 establecía un beneficio

\footnotetext{
${ }^{24}$ Letelier (1887-1908) Sesión de la Cámara de Diputados del 29 de julio de 1833, Tomo XXII, p. 77.

25 Letelier (1887-1908) Tomo XXII, p. 79. No deja de resultar irónico que la primera ley chilena dirigida a proteger la "propiedad literaria" haya utilizado, en su mensaje, un párrafo íntegro de la REAL CÉDULA de 1764 dictada por Carlos III.
} 
en favor de los herederos del autor, quienes gozarían de los beneficios de aquel por un plazo de cinco años, prorrogables hasta diez al arbitrio del Gobierno.

Todos los artículos mencionados fueron tomados de la Ley francesa de 19 de julio de $1793^{26}$, relativa a los falsificadores. La influencia de dicha norma no es tan solo en espíritu, sino que literal, ya que el artículo primero del proyecto chileno antes reproducido, es prácticamente una traducción de su equivalente francés ${ }^{27}$. Lo mismo sucede con los otros dos artículos mencionados ${ }^{28}$.

Además de los artículos ya expresados, el resto del proyecto establecía también ciertos grados de protección sobre obras de carácter póstumo y obras publicadas por extranjeros, a quienes se extendía una idéntica protección que a los autores chilenos. Asimismo se establecía la posibilidad de que el autor de una obra fuese un cuerpo colegiado, en cuyo caso la protección se otorgaba por un plazo de 40 años desde su primera publicación. Esta norma debe de haber obedecido a la necesidad, planteada ya por Carlos III en 1778, de otorgar cierto grado de protección a las obras elaboradas en las Universidades y otros centros de estudio (como las Reales Academias).

El proyecto recibido fue pasado a la Comisión de Legislación, y archivado mientras esta lo discutía. De esta guisa, la Comisión informó favorablemente sobre el proyecto con fecha 9 de agosto del mismo año, con lo que el proyecto pasó a ser discutido en la Sala de la Cámara de Diputados, corporación donde había sido recibido el Proyecto. Este se discutió y aprobó en general con fecha 22 de noviembre, y en particular con fechas 13 y 16 de diciembre. Por algún motivo del cual no ha quedado registro, en la sesión del 13 se aprobaron todos los artículos, salvo el 7, 10 y 13, los que fueron aprobados el día 16. En definitiva, el Proyecto del ejecutivo fue aprobado sin modificaciones por la Cámara de Diputados, la que lo remitió al Senado. En esta corporación fue recibido con fecha 9 de junio de 1834, y pasó a ser discutido y aprobado el 18 y 20 del mismo mes, sin modificación ni indicación alguna. Volvió de este modo a la Cámara de Diputados con fecha 27 de junio, dándose cuenta al Presidente de la República de su aprobación con fecha 4 de julio. Fue definitivamente promulgado con fecha 24 de julio de $1834^{29}$. Con esto, Chile se convirtió en uno de los primeros países en regular legislativamente sobre la materia ${ }^{30}$.

\section{Contenido y aplicación de la ley de Propiedad Literaria de 1834}

La ley aprobada constaba de 15 artículos. La ley establecía una protección vitalicia en favor de los autores de distintas obras (escritos, composiciones de música, esculturas, pinturas, etc.), quienes gozaban del derecho de reproducción de la obra. Si bien la ley

\footnotetext{
26 GuZMÁn (2005) p. 58.

27 Art. 1. Les auteurs d'ecrits en tout genre, les compositeurs de musique, les peintres et dessinateurs qui feront graver des tableaux ou dessins, jouiront, durant leur vie entiere, du droit exclusif de vendre, faire vendre, distribuir leurs ouvrages dans le territoire de la republique, et d'en ceder la propieté en tout ou en partie.

28 El artículo 2 de la citada ley francesa señalaba: "Leurs heritiers ou cessionnaires jouiront du meme droit, durant l'espace de dix ans, apres la mort des auteurs".

29 LiRA (1879) Libro III, p. 55.

30 De acuerdo a Alberto Cerda, Chile fue de los países que más temprano dictaron leyes para regular la materia, con leyes en Colombia el mismo año, Venezuela en 1839 y Perú en 1849. Cerda (2016) p. 25.
} 
no hacía mención expresa a la distinción entre Derecho de Autor y derechos conexos, se entiende que estos estaban presentes en el espíritu de la norma, la que permitía al autor "vender, hacer vender o distribuir..." (art. 1), es decir, por sí o por cuenta de terceros. El artículo tercero señalaba expresamente que tanto el autor como sus herederos podían transmitir sus derechos a terceros. Los herederos podían disfrutar de dicha protección por un tiempo reducido de 5 años, prorrogable hasta 10. Se aprobó la protección de 40 años para los autores que fuesen un cuerpo colegiado, y se establecía que los derechos de autor nacían no del acto administrativo que concedía el privilegio exclusivo de propiedad literaria, sino que existían desde su creación (art. 10).

Precisamente a propósito de esta disposición es que se suscitó un interesante pleito entre dos conocidos profesores, y el fisco junto a uno de ellos ${ }^{31}$. Los hechos fueron los siguientes: el abogado Gonzalo Cruz, profesor de Geografía del Instituto Nacional, publicó una obra titulada Geografía para las Escuelas, que llegó a contar con ocho ediciones. Al mismo tiempo, el Gobierno de Chile encargó al también abogado y precursor de la educación chilena don Abelardo Núnez la elaboración de un texto de geografía que sirviera para reemplazar el hasta entonces utilizado. Para ello, Núñez se acercó a la casa de Cruz, a quien intentó persuadir de ceder los derechos sobre su libro a cambio de diez mil ejemplares de la edición proyectada (de veinte mil), o bien la suma de cinco centavos por cada ejemplar vendido, opciones que el autor desestimó. Pese a ello, Núñez procedió de igual modo a la publicación del libro de Cruz bajo el título de Geografía de los Niños, publicada en Alemania.

Cruz presentó una demanda, resultando perdedor en primera instancia. Dicha sentencia, luego de largos considerandos en los que pondera la originalidad de la obra y la posible infracción de la Ley de Propiedad Literaria, concluye que el demandante no había constituido propiedad literaria sobre su obra por no haber dado cumplimiento a los requisitos señalados en el artículo 10, esto es, el haber depositado tres ejemplares de la obra en la Biblioteca Pública de Santiago, y el haberse anunciado en el frontispicio ${ }^{32}$ la autoría. La Corte de Apelaciones de Santiago confirmó la sentencia de primera instancia, y dio un paso más al señalar que precisamente por no haberse cumplido con el trámite del depósito, la obra del Sr. Cruz debía considerarse "propiedad común". Pese a dicho revés, resulta interesante el considerando $6^{\circ}$ de dicha sentencia, que distingue claramente entre el derecho de autor y los derechos conexos. Para el sentenciador, “... como las producciones de la inteligencia una vez publicadas por sus autores se convierten por su propia naturaleza en propiedad común, desde que todos pueden asimilárselas y aprovecharse de ellas, la ley de 1834, para el solo efecto de amparar la utilidad pecuniaria que puede obtenerse con la reproducción por medio de la imprenta o de otro modo, exige como requisito indispensable se anuncie a quién pertenecen las dichas producciones..."33. De acuerdo a la sentencia del

\footnotetext{
31 La reproducción de las partes relevantes de todo el proceso fueron publicadas por CRUZ (1907).

32 Esta exigencia es, en nuestro juicio, ambigua. Efectivamente el artículo 10 señala “...y bastará que depositándose previamente tres ejemplares en la Biblioteca pública de Santiago, se anuncie en el frontispicio a quien pertenezca". Cuando se pide la exigencia del anuncio, no queda claro si se refiere al frontispicio del libro, o bien de la Biblioteca pública de Santiago.

33 Cruz (1907) p. 242.
} 
Tribunal de Alzada, la ley reconocía la distinción entre ambas caras del Derecho de Autor. Como fuere, dado el revés sufrido en segunda instancia, el perjudicado autor recurrió hasta la Corte Suprema, la que confirmó la sentencia del tribunal de alzadas. El argumento del máximo tribunal, al igual que el del tribunal de alzada, se apoya en la falta de cumplimiento de los requisitos establecidos en el artículo 10 de la ley. No obstante, en cuanto al fondo del asunto, en su considerando $7^{\circ}$ la Corte Suprema expresamente reconoció que “...según la prueba rendida en esta causa y especialmente según el informe de fojas 75 suscrito por don Eliodoro Yáñez, don Roberto Huneeus y don Adolfo Tapia, y el de fojas 344 suscrito por don Gaspar Toro, la dicha Geografía de los niños es casi en su totalidad una reproducción literal del libro de don Gonzalo Cruz titulado Geografía para la enseñanza secundaria”. En definitiva, la Corte Suprema, si bien confirmó la sentencia de segunda en cuanto a que los requisitos señalados en el artículo 10 de la ley tenían lugar "para el solo efecto de amparar la utilidad pecuniaria", no separó la protección de los derechos conexos del derecho de autor, negando en definitiva que se tratase de un plagio. Si bien la Corte Suprema reconoció la existencia de derechos conexos separados de los de autor, no aprovechó la oportunidad para salvar estos últimos, desestimando la demanda en todas sus partes. El Sr. Cruz manifestó su disconformidad al señalar en sus comentarios a todo el proceso que "con la referida sentencia, la propiedad literaria queda en Chile a merced de los tribunales...." ${ }^{34}$.

\section{LEY DE PRIVILEGIOS EXCLUSIVOS DE 1840. SITUACIÓN PREVIA A SU DICTACIÓN}

\section{HiSTORIA Y FUENTES DE LA LEY}

Como hemos visto, la Propiedad Literaria quedó regulada por una Ley de la República desde 1834. Sin embargo, antes de que esta fuese aprobada, las obras de los autores quedaban protegidas por las leyes españolas, vigentes en Chile en cuanto no contraviniesen el nuevo estado político del país. Ese razonamiento es el que nos llevó a sostener que la Real Cédula de Carlos III promulgada en 1778 fue la norma vigente hasta la promulgación de la ley que acabamos de comentar.

En cuanto a los privilegios industriales la situación debería de haber sido análoga, no obstante, el Gobierno demoró la tramitación de la ley de privilegios industriales 7 años más de lo originalmente propuesto en el mensaje de 1833, período durante el cual el país, no obstante contar con protección industrial a nivel constitucional, no contó con una legislación técnica sobre la materia. Ello no significa que el artículo 152 de la Constitución haya sido letra muerta en lo que a protección de privilegios industriales se refiere, y muy por el contrario, se puede contar un elevado número de privilegios - patentes- concedidas a solicitantes. La tramitación era engorrosa y dilatada, toda vez que para obtener dicha solicitud se debía presentar la solicitud ante el Gobierno, el cual la remitía al Congreso para su aprobación bajo la forma de ley. En consecuencia, la protección industrial durante aquellos años dependió de una Ley de la República, y no de un acto administrativo del Gobierno.

34 Cruz (1907) p. 261. 
La principal diferencia en relación con la Propiedad Literaria antes vista radica en que en el Derecho Español no se contó con una ley de Privilegios Industriales similar a la citada Real Cédula de 1778. Por el contrario, estos privilegios se concedían caso a caso, y la normativa que los contemplaba no era uniforme. Así por ejemplo, en el caso chileno, la principal norma relativa a la protección de los inventos relativos a la industria era aquella que regulaba el principal sector industrial de entonces: la Real Ordenanza de Minería. Esta ley, aprobada por Carlos III en 1778 y aplicadas en Chile en 1787 durante el interinato de Tomás Álvarez de Acevedo ${ }^{35}$, establecía en las leyes 17, 18 y 19 de su Título XVIII, la concesión de privilegios a aquellas personas que, ora por su ingenio, ora por haber viajado a otros países, solicitara protección para los inventos que presentasen ${ }^{36}$. Por supuesto, se entiende que la norma hace referencia a inventos relativos a la minería, y no a otros rubros. De esta manera, la Real Ordenanza de Minería fue aplicada en Chile tras la Independencia sin cuestionar su origen monárquico apenas se afianzó la Independencia. Por ejemplo, el 28 de julio de 1817 se presentó una solicitud de privilegio exclusivo por parte de Santiago Heitz, para poder implementar unas "máquinas desconocidas en el país” y gozar de protección en su industria ${ }^{37}$. Idéntica protección solicitó Manuel Rojas en 1831 y Onofre Bunster en 1832. En ambos casos, recibida la Propuesta del Gobierno (que había subrogado en esta competencia al Tribunal de Minas tras su disolución en 1818) por parte del Congreso, fue la Comisión de Hacienda de la Cámara de Diputados la que optó siempre por devolver asunto al Ejecutivo, encargándole resolver de acuerdo a los citados artículos 17 y 18 del Título XVIII de la Ordenanza de Minas. Y así resolvió el Gobierno.

Ahora bien, es importante destacar que no todas las solicitudes de privilegio presentadas antes de 1833 recayeron sobre inventos aplicables a la minería, y en consecuencia dicha norma no constituyó el marco general bajo el cual se resolvían las solicitudes presentadas. De esta forma, ya en 1819 podemos identificar la solicitud de J. Robinson para que se le conceda un privilegio exclusivo de 15 años sobre un invento que le permitía elaborar licores con el uso de una máquina de vapor (un alambique) ${ }^{38}$. El Senado Conservador se lo concedió por 6 años ${ }^{39}$. Un caso similar y que presenta gran interés es el del ciudadano norteamericano Daniel Grinol, quien en 1821 elevó ante el Senado Conservador una solicitud de privilegio industrial para introducir en Chile la navegación a vapor, favoreciendo el cabotaje $e^{40}$. Ante la distendida protección de 15 años solicitada por Grinol, el Senado optó por solicitar informe del Consulado, que como gremio de comerciantes, podría ilustrar bien el asunto ${ }^{41}$. Llama la atención parte del razonamiento del Senado, que miraba con

\footnotetext{
35 Dougnac (1999) pp. 111-158.

36 Es especialmente importante el artículo 18, que señalaba: "Los inventos útiles y aprobados que después de verificado en grande se calificaren por el uso corriente de más de un año, serán premiados con privilegio exclusivo durante la vida de su autor para que nadie use de ellos sin su consentimiento, y sin contribuirle con una moderada parte del provecho y ventaja que efectivamente resultare del uso de la tal invención”.

37 LeTELIER (1887-1908) Tomo VIII, p. 437.

38 Letelier (1887-1908) Tomo III, p. 86.

39 Letelier (1887-1908) Tomo III, p. 103.

40 Letelier (1887-1908) Tomo V, p. 33.

41 Letelier (1887-1908) Tomo V, p. 41.
} 
cierto recelo la introducción de esta nueva tecnología: "Tres objeciones han aparecido hasta aquí contra la adopción de este proyecto, tales son: 1a. Que el por la exigua porción de brazos que requiere para las maniobras mar, arruina en su origen los progresos de nuestra marina, destruyendo el plantel de marineros, que todas las naciones han fijado en el comercio de cabotaje..." ${ }^{\prime 2}$.

Tras recibir el informe del Consulado, el Senado Conservador otorgó al señor Grinol el privilegio solicitado, pero por el plazo de 10 años, y la obligación de introducir la navegación a vapor dentro del plazo de 18 meses, transcurridos los cuales expiraría el privilegio de no iniciarse las actividades ${ }^{43}$. Hubo otras solicitudes, como las de Diego Antonio Barros, quien solicitó un privilegio por 6 años para establecer una fábrica de cebo colado, cueros, crin y lana, a quien se le concedió finalmente por 4 años $^{44}$. El mismo plazo de protección se le concedió por la Convención Preparatoria de 1822 a José Manuel Hernández y José Antonio Díaz, quienes lo solicitaron para establecer una fábrica de jabón y velas de aceite de ballenas ${ }^{45}$.

En 1824 se propuso una medida interesante, que buscaba fomentar el progreso y desarrollo del país mediante el incentivo a la colonización extranjera. Esta ley establecía el otorgamiento de protección a los privilegios industriales que los extranjeros trajesen consigo, aunque sin desarrollar mayormente el punto y dejando el asunto bajo la fórmula "en cuanto pueda el Gobierno" ${ }^{\text {46 }}$.

Sin embargo, el Gobierno dio los primeros pasos en miras a conseguir una ley que regulase la Concesión de Privilegios Industriales a través de una ley especial en 1831, justamente a propósito de la presentación que el Vicepresidente Fernando Errázuriz hizo de la solicitud del artesano Manuel Rojas, vista más arriba. En ella, Errázuriz señalaba: "Pero no debiera limitarse el Congreso únicamente a resolver sobre la solicitud de este individuo. Una ley sobre privilegios de invención es de urgente necesidad en nuestro país para fomentar la industria naciente, que en tanto permanezca privada de estímulos nunca se levantará del polvo. A juicio del Gobierno, debiera especificarse en dicha ley los privilegios a que son acreedores los autores de una invención enteramente nueva y de conocida utilidad pública; aquellos de que deben gozar los introductores de una máquina conocida en otros pueblos, pero desconocida en el nuestro, que emplee primeras materias del país; aquellos de que puedan gozar las que carezcan de esta última condición; una ley, en fin, que teniendo presente los casos que pueden ocurrir con más frecuencia, premie los talentos y favorezca las empresas útiles a la sociedad" 47 .

Dado que al parecer el Congreso hizo caso omiso de la sugerencia de Errázuriz, es que el Presidente Prieto intentó nuevamente insistir en la conveniencia de contar con una ley de esta naturaleza, aprovechando el mensaje con el que acompañaba la solicitud de

42 Letelier (1887-1908) Tomo V, p. 34.

43 Letelier (1887-1908) Tomo V, p. 84.

44 Letelier (1887-1908) Sesiones del 13 y 15 de abril, Tomo V, pp. 601 y 607.

45 Letelier (1887-1908) Tomo VI, p. 389.

46 Letelier (1887-1908) Tomo IX, p. 245.

47 Letelier (1887-1908) Sesión del 11 de julio de 1831, Tomo XIX, p. 127. 
Onofre Bunster. En dicha oportunidad Prieto señaló: "El Gobierno recomienda nuevamente al Congreso la necesidad de una ley sobre esta materia, satisfecho plenamente de que esta sola medida hará progresar con rapidez todos los ramos de industria que aún yacen en un abatimiento extremo" ${ }^{48}$.

Estas propuestas no tuvieron acogida por parte del Congreso, lo que quizá se deba a la dedicación de los esfuerzos en torno a la Convención Constituyente que daría origen a la Constitución de 1833, la que una vez aprobada, estableció el primer antecedente de protección constitucional a la propiedad intelectual, como ya vimos. Desde el punto de vista de la propiedad industrial, este artículo vino a introducir un cambio en la norma que justificaba la protección industrial, incluso en el rubro minero, en el que las Reales Ordenanzas de Minería de Nueva España seguían plenamente vigentes como Ordenanzas de Minería. Tal es el caso de dos profesores franceses, Juan Lay - profesor ebanista- y José Coupelon -profesor dentista-, quienes en 1833 solicitaron un privilegio exclusivo por 10 años para explotar minas de mármol, jaspe y otras piedras preciosas. En su solicitud, los franceses no dudaron en invocar la Constitución en su defensa, a tan solo un par de semanas desde su promulgación (25 de mayo de 1833): “...Protestamos que nada exigimos que no sea conforme a la Constitución y leyes del país o, por mejor decir, que no emane y parta de ellas mismas. Una administración tan liberal y tan celosa de promover los adelantamientos y prosperidad pública, no puede menos de acoger benignamente nuestra petición sumisa...”49.

Dada la falta de una ley especial que regulase la materia, los solicitantes argumentaban su petición en la ley dictada en 1811 -no obstante ellos la databan en 1813-que regulaba las aduanas y el comercio libre, citando expresamente algunos de sus artículos -especialmente aquellos que establecían exenciones tributarias- de los que se podría desprender cierto grado de fomento al desarrollo industrial y la consecuente protección industrial sobre los inventos e innovaciones ${ }^{50}$.

Un caso importante de protección industrial fue el solicitado por William Wheelwright en 1835. El Presidente Prieto presentó la solicitud ante el Senado con fecha 12 de junio de ese mismo año -y acompañó un proyecto de ley al respecto-, corporación que, a diferencia de casos anteriores, radicó la discusión de los pormenores en la Comisión de Gobierno -y no en la de Hacienda- ${ }^{51}$. La comisión sugirió aprobar el

\footnotetext{
48 Letelier (1887-1908) Sesión del 12 de septiembre de 1832, Tomo XIX, pp. 440-441.

49 Letelier (1887-1908) Sesión del 14 de junio de 1833, Tomo XXII, p. 11. Un año más tarde, Miguel Navas solicitaría protección de privilegio exclusivo sobre un invento de su autoría para la fabricación de untos para botas. En su solicitud, Navas señalaba expresamente que justificaba su solicitud ante el Congreso "porque aún no se dictaba la ley que previene el artículo 152 de la Constitución...”. SCL, Sesión del 14 de julio de 1834, Tomo XXII, p. 352.

50 El artículo 4 resume bastante bien el espíritu de dicha pieza de legislación en torno al tratamiento del desarrollo científico por parte del Primer Congreso Nacional: "Art. 4. Con el fin de dar mayor fomento a las ciencias, a la agricultura e industria del país, se encarga a los maestres y capitanes de todo buque que conduzcan al Reino sin costo ni gravamen alguno, a todo científico, especialmente matemáticos, químicos, botánicos y artesanos, invitándolos al efecto, ciertos de que, a más de satisfacerles del erario los costos, serán tratados los conductores como Beneméritos de la Patria, por concurrir a propagar en estas poblaciones los conocimientos útiles, que proceden a la Industria, y hacen florecer el Comercio". Ley de Comercio y Navegación. Ordenanza de Aduanas, 1811. Anguita (1902) pp. 6-7.

51 Letelier (1887-1908) Tomo XXIII, pp. 332-336.
} 
proyecto presentado por el Presidente en la sesión siguiente, aprobando el Senado todos sus artículos en las sesiones del 6 y 8 de julio. Como se puede apreciar, a diferencia de la solicitud presentada por Daniel Grinol en 1821, en esta oportunidad la tramitación fue bastante expedita, y no se presentó objeción alguna fundada en los inconvenientes que el desarrollo tecnológico pudiese tener en la marinería nacional. El proyecto fue derivado a la Cámara de Diputados, la que lo recibió el 17 de julio, y lo aprobó en general el 22 y en particular el 27 del mismo mes, siendo promulgada como ley el 25 de agosto de 1835. En total, la tramitación de este privilegio no tardó más de tres meses, y tuvo como resultado la introducción de la navegación a vapor en Chile ${ }^{52}$.

Como vemos, el hecho de no contar con una ley ordinaria que regulase la concesión de patentes de propiedad industrial no fue obstáculo para la concesión de las mismas, o bien para la introducción de nuevas tecnologías en el país. Ahora bien, es preciso recordar que en el mismo mensaje en el que el Presidente Prieto presentaba al Congreso el Proyecto de Propiedad Literaria de 1833, hacía presente que también era necesario contar con una ley de privilegios industriales, que se reservaba para una posterior presentación. La razón que el Presidente entregaba para optar por esta discusión diferida de ambas materias decía razón con que "Los [privilegios] que en todos los pueblos cultos se conceden a los inventores de máquinas o instrumentos que tengan por objeto facilitar las operaciones de la agricultura o de las artes mecánicas, son siempre más limitados que los que se conceden a los escritores. Los de estos ningún perjuicio causan a las naciones, antes bien, protegen la aplicación al estudio y el descubrimiento de nuevas verdades, y aquellos, aunque en sumo grado ventajoso, pueden arruinar en un momento un ramo general de industria con provecho tan solo del inventor; el Gobierno quisiera por tanto, ser tan sobrio para conceder los de esta clase, como franco para declarar aquellos...".

Fiel a ese mensaje, el Ejecutivo retrasó la presentación del Proyecto que regulaba los Privilegios Industriales, y de hecho nunca presentó un proyecto redactado, como sí había hecho con la Ley de Propiedad Literaria. Recién el 8 de julio de 1840, ante la solicitud de un privilegio en particular presentado por José Luis Calle, el Ministro del Interior y Vicepresidente en ejercicio don Joaquín Tocornal aprovechó la oportunidad para sugerir al Senado la conveniencia de iniciar la discusión de una Ley de Privilegios que se encargara de regular aquellos puntos previstos en el artículo 152 de la Constitución no tratados en la Ley de Propiedad Literaria de 1834. El mismo magistrado sugería que ante la demora propia de la discusión de una ley como la propuesta, era conveniente que se aprobase una ley transitoria que autorizase al Ejecutivo para conceder estos Privilegios Industriales sin tener que recurrir particularmente al Congreso cada vez que una solicitud fuese presentada ${ }^{53}$.

\footnotetext{
52 Otra solicitud de 1835 lleva la firma de Andrés Blest -tío del escritor Alberto Blest Gana- para obtener el privilegio exclusivo sobre un invento suyo para destilar ron en Valparaíso. Letelier (1887-1908) Sesión del 7 de septiembre de 1835, Tomo XXIII, p. 431.

53 “... Y como nuestra industria favorecida por leyes sabias que la protegen y la fomentan, convida a empresas difíciles que para plantearse necesitan las más veces el aliciente de un privilegio, el Gobierno se ve obligado a entender en esta clase de pedimentos y llamar continuamente la atención del Congreso. Estas consideraciones le han hecho sentir la necesidad de iniciar una ley sobre privilegios que amplificando el artículo 152 de la
} 
La solicitud del Vicepresidente Tocornal tuvo acogida en la Comisión de Hacienda y Artes del Senado, la que el 10 de julio presentó su conformidad con la solicitud presentada en lo principal del mensaje de aquel, y recomendó la tramitación y aprobación de una ley transitoria que regulase la materia, “...para que [el Supremo Gobierno] no haya de ocurrir al Congreso en cada caso particular, lo que ocasiona frecuentemente largas dilaciones..." 54 . El Proyecto de una ley provisoria elaborado por la citada comisión fue presentado ante la sala del Senado el día 15 de julio, la que aprobó los primeros dos artículos de los tres originalmente propuestos. A grandes rasgos, el artículo primero establecía la prerrogativa exclusiva del Gobierno para conceder dichos beneficios por un plazo que no podía superar los 10 años, mientras que el artículo segundo se limitaba a señalar que todos los inventos quedarían, en el futuro, regulados por la ley general que se dictase para el ramo. El artículo tercero -que se limitaba a establecer la obligación del Ejecutivo de velar y proteger estos privilegios- no fue aprobado -sin expresión de causa ${ }^{55}$.

Pese al avance que este proyecto provisorio significaba, en la sesión siguiente el Senador Diego José Benavente presentó un proyecto alternativo -con pretensión definitiva y no provisoria-, y solicitó que se suspendiera la tramitación del provisorio. La sala votó por 11 votos contra dos (de los trece asistentes) que aquel siguiera su tramitación, al tiempo en que se pasaba la propuesta del Senador Benavente a la misma Comisión de Hacienda y Artes. En los hechos, ello significó que el proyecto provisorio no fuese nuevamente discutido.

\section{La discusión de la Ley sobre Privilegios ExClusivos}

El "Proyecto de ley sobre privilegios exclusivos redactado por don D.J. Benavente" pasó entonces a la Comisión de Hacienda, la que comenzó a discutirlo rápidamente y recomendó su aprobación en la sesión del 20 de julio. Este proyecto constaba de 16 artículos, y fue pasado en la misma sesión a la Comisión de Hacienda del Senado. En este punto se produce una confusión inexplicable en la tramitación del Proyecto de Benavente, ya que la Comisión informa favorablemente el día 22 del mismo mes, y por lo mismo el proyecto se coloca en tabla para ser discutido en la sesión del Senado de ese mismo día, corporación que acuerda "Aprobar en general y en particular en la forma en que consta en el acta, el proyecto de ley propuesto por el Señor Benavente". El problema radica en que el proyecto que se reproduce en el acta consta de 17 artículos, y no de los 16 originalmente presentados por Benavente. Tampoco queda constancia de que en la comisión se haya discutido el proyecto en particular, o indicación expresa de la misma comisión en el sentido de añadir

Constitución, determine los casos en que han de darse, y fije el tiempo que deban durar...”. Mensaje de Joaquín Tocornal vista en la sesión del 8 de julio de 1840. Letelier (1887-1908) Tomo XXVIII, Anexo 217, p. 293.

54 Letelier (1887-1908) Sesión del 10 de julio de 1840, Tomo XXVIII, p. 299.

55 Letelier (1887-1908) Sesión del 15 de julio de 1840, Tomo XXVIII, p. 309. El proyecto presentado por la Comisión establecía lo siguiente: "Artículo 1. Se autoriza al Presidente de la República para determinar provisoriamente y hasta que se dicte la ley a que se refiere el artículo 152 de la Constitución, el tiempo porque deban durar los privilegios exclusivos, con tal que no exceda de 10 años. Artículo 2. Los privilegios que el Presidente de la República concediere, quedarán sujetos a la ley general que debe dictarse sobre esta materia. Artículo 3. El Presidente de la República tomará las medidas que conceptuase convenientes para que no se hagan ilusorios los privilegios concedidos". 
InfANTE MarTin, Javier — "Proteger lo original: consideraciones en torno a la protección de la propiedad ..."

un artículo nuevo a dicho proyecto ${ }^{56}$. Creemos conveniente reproducir ambos artículos en la siguiente tabla, en la que hemos resaltado algunas de las diferencias:

\begin{tabular}{|c|c|}
\hline Proyecto de Benavente & Proyecto modificado \\
\hline $\begin{array}{l}\text { Art. 1. El autor o inventor de un arte, manu- } \\
\text { factura, máquina, instrumento, preparación } \\
\text { de materias o cualquiera mejora en ellas que } \\
\text { pretenda gozar de la propiedad exclusiva que } \\
\text { le asegura el artículo } 152 \text { de la Constitución, } \\
\text { se presentará al Ministro del Interior, hacien- } \\
\text { do una descripción fiel, clara y sucinta de la } \\
\text { obra o invento, jurando que es descubrimiento } \\
\text { propio, desconocido en el país, acompañando } \\
\text { muestras, dibujos o modelos, según lo permita } \\
\text { la naturaleza de los casos, y solicitando una pa- } \\
\text { tente que acredite su propiedad. }\end{array}$ & $\begin{array}{l}\text { Art. 1. El autor o inventor de un arte, manu- } \\
\text { factura, máquina, instrumento, preparación } \\
\text { de materias o cualquiera mejora en ellas que } \\
\text { pretenda gozar de la propiedad exclusiva que } \\
\text { le asegura el artículo } 152 \text { de la Constitución, } \\
\text { se presentará al Ministro del Interior, hacien- } \\
\text { do una descripción fiel, clara y sucinta de la } \\
\text { obra o invento, jurando que es descubrimiento } \\
\text { propio, desconocido en el país, acompañando } \\
\text { muestras, dibujos o modelos, según lo permita } \\
\text { la naturaleza de los casos, y solicitando una pa- } \\
\text { tente que acredite su propiedad. }\end{array}$ \\
\hline $\begin{array}{l}\text { Art. 2. El Ministro del Interior nombrará una } \\
\text { comisión de uno o más peritos para que exami- } \\
\text { ne la obra o invención y le informe so sobre su } \\
\text { originalidad. }\end{array}$ & $\begin{array}{l}\text { Art. 2. El Ministro del Interior nombrará una } \\
\text { comisión de uno o más peritos para que exami- } \\
\text { ne la obra o invención y le informe so sobre su } \\
\text { originalidad. }\end{array}$ \\
\hline $\begin{array}{l}\text { Art. 3. Averiguada esta, el Presidente de la Re- } \\
\text { pública, con acuerdo de su Consejo de Estado, } \\
\text { concederá el privilegio exclusivo por un tér- } \\
\text { mino que no exceda de diez años, y mandará } \\
\text { extender la respectiva patente, que será auto- } \\
\text { rizada con su firma y sellada con el sello de la } \\
\text { República. }\end{array}$ & $\begin{array}{l}\text { Art. 3. Averiguada esta, el Presidente de la Re- } \\
\text { pública concederá el privilegio exclusivo por } \\
\text { un término que no exceda de diez años, y man- } \\
\text { dará extender la respectiva patente, que será } \\
\text { autorizada con su firma y sellada con el sello de } \\
\text { la República. }\end{array}$ \\
\hline $\begin{array}{l}\text { Art. 4. Esta patente será registrada íntegra en } \\
\text { un libro que al efecto se llevará en la oficina del } \\
\text { Ministerio del Interior. }\end{array}$ & $\begin{array}{l}\text { Art. 4. Esta patente será registrada íntegra en } \\
\text { un libro que al efecto se llevará en la oficina del } \\
\text { Ministerio del Interior. }\end{array}$ \\
\hline
\end{tabular}

${ }^{56}$ Véanse las sesiones del 20 y 22 de julio de 1840. Letelier (1887-1908) Tomo XXVIII, pp. 311 y 317. 
Art. 5. Antes de entregarse la patente al que la solicita, hará constar por los correspondientes recibos, el haber entrado en Tesorería General la cantidad de $\$ 25$, y de haber depositado en el Museo Nacional, dibujos o modelos y un pliego cerrado que contenga una descripción tan minuciosa y especificada, que distinga la invención o descubrimiento de las otras cosas antes conocidas y usadas, que señale los diversos modos y principios de que se puede valer en su aplicación para que pueda habilitar a cualquiera otra persona perita en el arte o manufactura, para hacer construir o usar la misma invención a fin de que el público se aproveche del beneficio a la expiración del término de la patente. En la cubierta de este pliego se escribirá el título u objeto del privilegio, afirmará el propietario que ha llenado fielmente la condición aquí impuesta, y lo certificará la Comisión, jurando no revelar el secreto.
Art. 5. Antes de entregarse la patente al que la solicita, hará constar por los correspondientes recibos, el haber entrado en Tesorería General la cantidad de $\$ 50$, y de haber depositado en el Museo Nacional las muestras, dibujos y modelos y un pliego cerrado que contenga una descripción tan minuciosa y especificada, que distinga la invención o descubrimiento de las otras cosas antes conocidas y usadas, que señale los diversos modos y principios de que se puede valer en su aplicación para que pueda habilitar a cualquiera otra persona perita en el arte o manufactura, para hacer construir o usar la misma invención a fin de que el público se aproveche del beneficio a la expiración del término de la patente.

En la cubierta de este pliego se escribirá el título u objeto del privilegio, afirmará el propietario que ha llenado fielmente la condición aquí impuesta, y lo certificará la Comisión, jurando no revelar el secreto. El propietario durante el término de un privilegio, podrá examinar el pliego para ver si se mantiene cerrado y lacrado como lo entregó.

Art. 6. en el Museo Nacional se destinará una sala para colocar las muestras, modelos o dibujos y una [sic] arca segura para custodiar los pliegos cerrados de que habla el artículo anterior, los que no podrán ser abiertos ni publicados, mientras no haya expirado el término del privilegio o patente.

Art. 7. Los $\$ 25$ que previene el artículo $5^{\circ}$ se destinan para la conservación y fomento de la sala que se establece en el Museo.

Art. 8. La introducción de artes, manufacturas, máquinas inventadas en otras naciones y desconocidas enteramente o no establecidas ni usadas en Chile, podrán obtener privilegios exclusivos en los mismos términos y con las mismas condiciones que los nuevos descubrimientos o invenciones, pero por un tiempo más corto que las últimas. No gozarán de privilegios las simples variaciones o mudanzas de solo formas o proporciones de las máquinas o cosas antes establecidas.
Art. 6. en el Museo Nacional se destinará una sala para colocar las muestras, modelos o dibujos y una [sic] arca segura para custodiar los pliegos cerrados de que habla el artículo anterior, los que no podrán ser abiertos ni publicados, mientras no haya expirado el término del privilegio o patente.

Art. 7. Los $\$ 50$ que previene el artículo $5^{\circ}$ se destinan para la conservación y fomento de la sala que se establece en el Museo.

Art. 8. La introducción de artes, manufacturas, máquinas inventadas en otras naciones y desconocidas enteramente o no establecidas ni usadas en Chile, podrán obtener privilegios exclusivos en los mismos términos y con las mismas condiciones que los nuevos descubrimientos o invenciones, pero por un tiempo más corto que las últimas.

No gozarán de privilegios las simples variaciones o mudanzas de solo formas o proporciones de las máquinas o cosas antes establecidas. 
Art. 9. La propiedad del privilegio o patente es transmisible como toda otra, pero cuando se enajene por venta se avisará previamente al Ministerio del Interior, expresando los motivos que causan la enajenación y siendo justos se anotará en el libro la transferencia.

Art. 10. Cualquier persona que construya artículos privilegiados por el mismo método que conste del privilegio, pagará una multa que no baje de $\$ 100$ ni suba de 1000 , perderá los efectos que se le encuentren construidos, y las máquinas, ingenios, instrumentos o útiles de que se ha valido. El valor de todo será aplicado por mitad al Fisco o al propietario de la patente o privilegio.

Art. 11. El privilegio que se haya conseguido subrepticiamente, es decir, sobre falsos testimonios, o no siendo el inventor el que lo ha solicitado, o sobre una industria ya establecida en el país de la misma manera, será anulado inmediatamente, condenado en las costas del proceso del esclarecimiento, el que lo obtuvo, y castigado con una multa pecuniaria que no exceda de $\$ 1000$ ni baje de ciento, o con una prisión que no baje de tres meses ni pase de doce.

Art. 12. Si se suscitare pleito entre individuos que hayan obtenido patentes para la fabricación de unos mismos productos, será decidido por un arbitraje compuesto de un juez nombrado por cada parte y de un tercero que nombrará el Ministro del Interior, de entre los jueces de la Corte de Justicia.

Art. 13. Se concederán privilegios generales que tengan su efecto en todo el territorio de la República, o particulares que comprendan a uno, dos o más departamentos o provincias.

Art. 14. En todo privilegio que se conceda, se fijará un término proporcionado para el establecimiento de las máquinas, ingenios o manufacturas, y concluido el cual comenzará a correr el concedido privilegio.
Art. 9. La propiedad del privilegio o patente es transmisible como toda otra, pero cuando se enajene se avisará previamente al Ministerio del Interior, expresando los motivos que causan la enajenación.

Si los encontrase justos, se anotará en el libro la transferencia, y si no, procederá a hacer efectiva la disposición del artículo 11 .

Art. 10. Cualquier persona que construya artículos privilegiados por el mismo método que conste del privilegio, pagará una multa que no baje de \$100 ni suba de 1000 , perderá los efectos que se le encuentren construidos, y las máquinas, ingenios, instrumentos o útiles de que se ha valido. El valor de todo será aplicado por mitad al Fisco o al propietario de la patente o privilegio, salvo la acción de daños y perjuicios que a este corresponda.

Art. 11. El privilegio que se haya conseguido subrepticiamente, es decir, sobre falsos testimonios, o no siendo el inventor el que lo ha solicitado, o sobre una industria ya establecida en el país de la misma manera, será anulado inmediatamente, condenado en las costas del proceso del esclarecimiento, el que lo obtuvo, y castigado con una multa pecuniaria que no exceda de $\$ 1000$ ni baje de ciento, o con una prisión que no baje de tres meses ni pase de doce.

Art. 12. Si se suscitare pleito entre individuos que hayan obtenido patentes para la fabricación de unos mismos productos, será decidido por un arbitraje en única instancia compuesto de un juez nombrado por cada parte y de un tercero que nombrará el Ministro del Interior.

Art. 13. Se concederán privilegios generales que tengan su efecto en todo el territorio de la República, o particulares que comprendan a uno, dos o más departamentos o provincias.

Art. 14. En todo privilegio que se conceda, se fijará un término proporcionado para el establecimiento de las máquinas, ingenios o manufacturas, y concluido el cual comenzará a correr el concedido privilegio. 
Art. 15. Solo podrá concederse la renovación de una patente, cuando casos fortuitos u ocurrencias extraordinarias hagan merecedor de ella al privilegiado y sea solicitada por lo menos seis meses antes de la expiración del privilegio.

Art. 16. No se deroga por la presente ley lo establecido en la ordenanza de minería con respecto a los privilegios que se concedieren en este ramo.
Art. 15. Si al vencimiento del plazo concedido para el establecimiento no se plantease, no tendrá lugar el privilegio; y caducará después de planteado, se abandonare por más de un año, o si se adulteraran los productos, haciéndose inferiores a las muestras o modelos presentados.

Art. 15. Solo podrá concederse la renovación de una patente, cuando casos fortuitos u ocurrencias extraordinarias hagan merecedor de ella al privilegiado y sea solicitada por lo menos seis meses antes de la expiración del privilegio.

Art. 16. No se deroga por la presente ley lo establecido en la ordenanza de minería con respecto a los privilegios que se concedieren en este ramo, ni lo establecido en la ley de 24 de julio de 1834 , relativa a la propiedad de obras literarias y de bellas artes.

Como se puede apreciar, independientemente de que no se pueda conocer el origen de las modificaciones introducidas, ellas no son menores, especialmente en aquello que dice relación con la acción de daños que ahora se introduce en favor del titular de la patente o privilegio y que se ve vulnerado, en las condiciones de caducidad de las mismas patentes o privilegios, o bien en la exclusión de cualquier injerencia jurisdiccional por parte del Poder Judicial en la resolución de los litigios sobre propiedad industrial (Art. 12).

Cual haya sido el origen de esas modificaciones, es en ese estado que el Proyecto de Benavente pasó a la Cámara de Diputados, la que acusó recibo de su recepción en la sesión del 29 de julio del mismo año, y la derivó a la Comisión de Hacienda para su estudio. En el intertanto, en la sesión del 24 de julio la Cámara de Diputados leyó también un informe del Senado dando cuenta del Proyecto presentado por el Vicepresidente Tocornal, facultando provisoriamente al Gobierno para autorizar los privilegios exclusivos que fuesen solicitados. No fue nuevamente discutida ni aprobada, y la Cámara decidió suspender toda concesión de privilegios hasta que la ley general fuese aprobada ${ }^{57}$.

La versión recibida por la Cámara de Diputados coincide con la versión de 17 artículos aprobada por el Senado. La Comisión de Hacienda elaboró su informe el 31 de julio, el que quedó en tabla en la sesión del 3 de agosto del mismo año ${ }^{58}$.

Este informe contenía algunas indicaciones al proyecto pasado por el Senado, que decían relación con sus artículos $2^{\circ}, 5^{\circ}$ y $8^{\circ}$. En relación con el artículo segundo, sugería la Comisión que se agregase la obligación de tomar juramento a los peritos, en presencia del inventor solicitante, de guardar religiosamente el secreto que se les comunicaría. Se

\footnotetext{
57 Así sucedió con las peticiones de los señores Larraín y La Calle, que debían resolverse en la sesión del 3 de agosto de 1840. Letelier (1887-1908) Tomo XXVII, p. 133.

58 Letelier (1887-1908) Tomo XXVII, p. 132.
} 
sugería también modificar el artículo $5^{\circ}$ en cuanto a que la declaración del contenido del sobre debía ser certificado a satisfacción de la Comisión que lo había informado, ya que el juramento - de originalidad- se encontraba contemplado en el artículo $2^{\circ}$. Finalmente, se sugería modificar el artículo $8^{\circ}$ en cuanto a suprimir la referencia a "manufacturas" y reemplazarla por "industrias", para evitar la confusión con "mercaderías manufacturadas". Se sugería asimismo que el tiempo de protección a los privilegios concedidos al amparo de dicho artículo no pasaren de 8 años ${ }^{59}$.

El proyecto se mantuvo en tabla hasta la sesión del 17 de agosto, en la que se aprobó en general. En la sesión del 21 de agosto se aprobó en particular, y se aceptaron las indicaciones propuestas por la Comisión de Hacienda, salvo en sus indicaciones relativas al artículo $8^{\circ}$, el que se modificó en cuanto a que el plazo máximo de protección quedaba efectivamente reducido a 8 años, pero en atención a la "utilidad o dificultad de la empresa, a juicio del Ministerio, en vista del informe de la comisión" ${ }^{60}$.

Con las modificaciones señaladas el proyecto se dio por aprobado, y se devolvió al Senado para su discusión y aprobación. Esta corporación acusó recibo el 26 de agosto de 1840 , y acordó aceptar las indicaciones propuestas condicionado ello a que la Cámara de Diputados conservase la "última cláusula del artículo original" en referencia al artículo $8^{\circ}$. También se acordó comisionar al Senador Mariano Egaña, "para que hiciese presente en la otra Cámara este acuerdo... advirtiéndose que si no convenía dicha Cámara en ellas, pidiese la aprobación del acuerdo provisorio en que se autoriza al Presidente de la República para determinar el tiempo que deban durar los privilegios, ínterin se dicta la ley general..."61.

Asistió el Senador Egaña a la sesión de la Cámara de Diputados de fecha 28 de agosto, oportunidad en la que se aprobaron los artículos discutidos sin mayores modificaciones que la última propuesta por el Senado, y se remitió nuevamente el proyecto a esta corporación con tan solo una indicación relativa al artículo $6^{\circ}$, en cuanto a que la integridad del sobre depositado en custodia del Museo Nacional pudiese ser abierto para efectos de los artículos 11, 12 y 15 $5^{62}$. Esta indicación fue aprobada por el Senado en su sesión del 31 de agosto, quedando con ello aprobado el proyecto en general y particular. Dado que el Senado clausuró las sesiones ordinarias el primero de septiembre de acuerdo al artículo 52 de la Constitución de 1833, no obstante la ley fue promulgada el 9 de septiembre de $1840^{63}$.

\section{Comentarios, contenido e implementación de la ley de Privilegios de 1840}

La Ley de Privilegios Industriales fue largamente comentada por José Victorino Lastarria en sus Comentarios a la Constitución de 1833. Según el comentarista, la ley chilena se habría tomado de la francesa del 7 de enero de 1791. Ello lo señala a propósito de

\footnotetext{
59 Letelier (1887-1908) Tomo XXVII, p. 132.

${ }^{60}$ Letelier (1887-1908) Tomo XXVII, p. 179.

61 Letelier (1887-1908) Tomo XXVIII, p. 516.

62 Letelier (1887-1908) Sesión del 31 de agosto, Tomo XXVIII, p. 527.

63 Anguita (1902) pp. 333-334. Sobre este punto, Jorge Huneeus señaló que este documento tuvo únicamente naturaleza de decreto con fuerza de ley, lo que en su opinión hacía que este fuese nulo por haber sido dictado sin la facultad para ello por parte del Ejecutivo: "Así pues, si las disposiciones de este decreto pudieron tildarse fundadamente, antes de nada menos que de inconstitucionales...”. HuneEus (1889) p. 10.
} 
la implementación del principio o supuesto de que para el otorgamiento de una patente la novedad es requisito indispensable: "Este principio, sobre el cual reposa la legislación francesa relativa a la materia, es aplicable a nuestra ley, que es copia de aquella y que lo admite expresamente", señalaba Lastarria siguiendo al clásico tratadista Francés Emile Victor Foucart ${ }^{64}$. Precisamente a la luz de la ley francesa y de la obra de Foucart es que Lastarria desarrolla su análisis de la ley. En primer lugar, cita la Ley Francesa y a Foucart para reforzar la idea de la necesaria separación entre Propiedad Literaria -Propiedad Intelectual en sentido estricto o Derecho de Autor- de las Patentes de Invención -Propiedad Industrial-. Siguiendo a Foucart, Lastarria sostiene que son objeto de este último tipo de protección los inventos que tengan una aplicación industrial -artículo 2 de la Ley Francesa y 1 de la Ley Chilena- elemento que debía ser además novedoso (el artículo 2 de la Ley Chilena habla de originalidad) para quedar cubierto con la protección de patentes o privilegios, como mencionábamos en el párrafo anterior. De este modo, los inventos que no tenían esta aplicación industrial quedaban fuera del amparo de la norma, y debían acogerse a la protección de la Ley de Propiedad Literaria de 1834. Otra similitud mencionada por Lastarria dice relación con los tipos de patentes que se podían conceder, a saber, de invención, de mejora o perfeccionamiento y de importación, siempre a la luz de los principios antes mencionados (aplicación industrial y novedad u originalidad). Señalaba Lastarria que la Ley Chilena se apartaba del espíritu de la que le servía de modelo en las patentes de importación, las que se otorgaban, de acuerdo al artículo 8, a "la introducción de artes, industrias o máquinas inventadas en otras naciones y desconocidas enteramente en Chile", mientras que la norma francesa protegía la introducción de inventos desde el extranjero siempre y cuando allí también contasen con protección. Según Lastarria, la legislación nacional era "enteramente contraria a esos principios de economía social", por cuanto esta otorgaba protección "sin más requisito que el de ser desconocidas enteramente en Chile" ${ }^{35}$.

En cuanto a su contenido, la Ley de privilegios exclusivos de 1840 tuvo bastantes características particulares, tanto en su forma como en el fondo. Formalmente, podemos reconocer una ley original. De acuerdo a Lastarria el Senador Diego José Benavente tuvo a la vista la Ley francesa de 1791 al momento de presentar su proyecto ante el Senado, resulta de su comparación con esta y otras leyes entonces vigentes sobre la materia que esta es original de su autor. Por otra parte, de acuerdo a Pedro Breuer, la norma chilena se habría inspirado en la Patent Act estadounidense de $1836^{66}$.

\footnotetext{
64 Foucart (1839), en Lastarria (1856) p. 206.

65 Lastarria (1856) p. 208.

66 Breuer (1957) Tomo I, p. 32, citado en Larraguibel (1987) p. 8. Del simple cotejo de la Ley de Privilegios Exclusivos de 1840 con la Patent Act de 1836 resaltan algunos puntos importantes, tales como el uso de la palabra manufactura en esta última. En su sexta sección, la norma dice que la patente se podrá conceder sobre "any new and useful art, machine, manufacture, or composition of matter, or any new and useful improvement ony art, machine, manufacture or composition of matter, not known or used by others before his or their Discovery or invention thereof...”. Del orden de la enumeración señalada en la ley estadounidense se puede concluir con certeza que el legislador chileno de 1840 tuvo a la vista dicha norma, la que resulta casi idéntica. Al mismo tiempo, la utilización del término "manufactura", discutido precisamente por el Congreso chileno, encuentra su origen en la ley estadounidense. Esta última puede consultarse en Peters (1856) pp. 117-125. No hemos dado con pistas que puedan entregar luces sobre cómo es que el Senador Benavente conoció esta pieza de legislación
} 
Pese a dichas posibles concordancias, cuando hablamos de la originalidad de la Ley de Privilegios Exclusivos de 1840 no pretendemos decir, por supuesto, que los principios que la orientan hayan sido creados completamente ex novo por el legislador de 1840. Muy por el contrario, algunos elementos de la ley -tales como el uso del término patente ${ }^{67}$, la intervención del Ministerio del Interior, o la consignación del objeto protegido en un sobre cerrado- pueden haber sido tomados de las Leyes Francesas de 7 de enero y de 25 de mayo $1791^{68}$, mientras que el plazo de protección de 10 años debe de haber sido tomado de la propia tradición española y chilena, que como vimos anteriormente, fijaba normalmente la duración de un privilegio en ese plazo. En general se puede observar que la ley fue bastante completa en cuanto a la protección que entregaba, de momento que establecía una protección exclusiva, por 10 años, transferible y oponible a terceros. Se establecía una acción de indemnización de perjuicios en favor del titular contra quienes hicieran uso no autorizado de su patente o privilegio, y se establecía el carácter comerciable del mismo bien, permitiendo su enajenación en un sentido amplio ${ }^{69}$. Se radicaba la jurisdicción para conocer de la entrega de estos privilegios en el Gobierno, excluyendo completamente a los demás poderes del Estado, y especialmente al Poder Judicial. Los pleitos suscitados sobre un privilegio quedaban radicados en un tribunal arbitral colegiado de única instancia, cuya conformación dependía exclusivamente de la designación que hicieren las partes y el Ministerio del Interior. Se establecían multas en beneficio fiscal y particular para quienes vulnerasen una patente o privilegio, infracción que incluso podía llevar aparejada la pena de cárcel. Finalmente, la ley buscaba y promovía el adelanto industrial y científico no solo mediante la protección inflexible de patentes y privilegios, sino que establecía un plazo razonable para su protección e implementación, al tiempo en que castigaba a aquellos inventores que solicitaban una patente o privilegio que no explotaban.

En cuanto a su implementación, este fue inmediato. El mismo año de su promulgación se aprobó la primera patente al amparo de esta ley, que recayó en la solicitud que

extranjera, no obstante se podría suponer que, dado el estado de la industria y economía nacional, el entonces Encargado de Negocios de los Estados Unidos Richard Pollard, haya hecho llegar un ejemplar de dicha norma al Senador Benavente.

67 Si bien la Ley del 7 DE enero de 1791 utilizaba el término "patente", el Reglamento del 25 DE MAYO de ese mismo año introdujo el concepto de "brevet", en uso hasta nuestros días. En España el término fue introducido por vez primera en 1820, en la efímera Ley de 2 de octubre de 1820. Según Pella y Forgas, ello ocurrió “...no sé si por odio a la palabra privilegio, que había de sonar mal a los progresistas de 1820, por imitación de la ley de patentes francesa de 1791, o real y efectivamente por convicción propia”. Pella y Forgas (1892) p. 40.

68 Véanse los artículos 1, 2 y 3 de la Loi PORTANT RĖGLEMENT SUR LA PROPRIÉTÉ DES AUTEURS D’inVENTIONS \& DéCouvertes en tout genre D’industrie, promulgada en París el 25 de Mayo de 1791. Galiset (1829) p. 376. La LeY Del 7 DE ENERo de 1791 puede revisarse en Le Hodey (1790) pp. 201 y ss. Según el principal comentarista contemporáneo a esta legislación, José Victorino Lastarria, la ley chilena se habría tomado de la francesa del 7 de enero de 1791. Ello lo señala a propósito de la implementación del principio o supuesto de que para el otorgamiento de una patente la novedad es requisito indispensable: "Este principio, sobre el cual reposa la legislación francesa relativa a la materia, es aplicable a nuestra ley, que es copia de aquella y que lo admite expresamente”, señalaba Lastarria siguiendo al clásico tratadista Francés Foucart. LASTARRIA (1856) p. 206.

69 La ley chilena fue más restrictiva que la francesa de 1791, que se limitó a señalar que de las patentes se podía disponer como de una propiedad mueble (art. XIV). La ley chilena en cambio exigía el aviso al Ministro del Interior para su enajenación. 
mencionábamos anteriormente ${ }^{70}$, presentada en 1835 por Andrés Blest para destilar ron en Valparaíso ${ }^{71}$.

\section{CONCLUSIONES}

Como se pude apreciar, Chile contó desde muy temprano con una legislación apropiada relativa a la Propiedad Intelectual. Más allá de la ironía en ciertos aspectos de la presentación y discusión de los proyectos de leyes particulares, el Gobierno de Chile y el Congreso Nacional mostraron desde muy temprano interés por regular y salvaguardar la propiedad de autores e inventores, bajo la premisa de que en ambos casos era de justicia proteger la propiedad en todas sus formas, y las consecuencias que esa tendencia proyectaba en el desarrollo intelectual e industrial del país. En algunos aspectos dichas normativas resultan llamativas para la época, como por ejemplo la sustracción de los litigios sobre patentes de la justicia ordinaria y su consagración como caso de arbitraje especial y forzoso. La elección del arbitraje como solución de controversias no aparece como solución establecida en las normas de derecho comparado vistas, por lo que se trata de una solución original del Derecho Chileno, que ha probado su utilidad mediante la consagración de esta medida en el Derecho vigente. En este sentido, la legislación patria se aleja de la tradición al sustraer el conocimiento de este tipo de litigios de los magistrados ordinarios.

Asimismo la consagración constitucional del Derecho de Propiedad Intelectual realizado en la Carta 1833 ha servido de antecedente político hasta nuestros días, en que la Constitución vigente continúa brindando protección expresa sobre la propiedad de autores e inventores (art. $\left.19 \mathrm{~N}^{\circ} 25\right)$.

En definitiva, podemos concluir que la legislación chilena sobre Propiedad Intelectual fue suficiente para su época y contexto económico e intelectual, teniendo como prueba de ello la larga vigencia de las leyes dictadas.

\section{BIBLIOGRAFÍA CITADA}

Berkemeyer, Hugo (2009): "Desafíos de la Propiedad Intelectual”, en Velasco, Rodrigo y Morales, Marcos (coords.), Estudios de Derecho y Propiedad Intelectual. Colección de trabajos en homenaje a Arturo Alessandri Besa (Santiago, Editorial Jurídica de Chile), pp. 123-138.

Berkovitz, Rodrigo (2012): Manual de Propiedad Intelectual (Valencia, Tirant lo Blanch).

Brahm, Enrique (2007): Mariano Egaña. Derecho y Política en la fundación de la República Conservadora (Santiago, Centro de Estudios Bicentenario).

Breuer, Pedro (1957): Tratado de Patentes de Invención, Tomo I (Buenos Aires, AbeledoPerrot). Carrasco Albano, Manuel (1858): Comentarios sobre la Constitución Política de 1833 (Valparaíso, Imprenta y Librería del Mercurio).

\footnotetext{
70 Véase nota 50.

71 Montero (1913) p. 3.
} 
Caselli, Pedro (Ed.) (2010). Historia Gráfica de la Propiedad Industrial en Chile (Santiago, Instituto Nacional de Propiedad Industrial).

Cerda, Alberto (2016): "Evolución histórica del Derecho de Autor en América Latina”, en Ius et Praxis, Año 22, Vol. 1: pp. 19-58.

Cruz, Gonzalo (1907): Algo sobre Propiedad Literaria (Santiago, Imprenta Barcelona).

Dougnac, Antonio (1999): "Proyección de las Ordenanzas de Minería de Nueva España en Chile (1787-1874)”, Revista de Estudios Histórico-Jurídicos, Vol. XXI: pp. 111-158.

Foucart, Emile Victor (1839): Elements de Droit Public et Administratif, ou exposition methodique des principes du droit public positif avec l'indication des lois a l'appui (Paris, Videcoq).

García-Huidobro, Vladimir (1992): Legislación sobre Propiedad Industrial. Análisis, Jurisprudencia y guía práctica (Santiago, Editorial Jurídica de Chile).

GuZmán, Alejandro (2005): Estudios Dogmáticos de Derecho Civil (Valparaíso, Ediciones Universitarias de Valparaíso).

HuneEus, Jorge (1889): Los privilegios exclusivos en Chile. Estudio de la legislación vigente y de la conveniencia de su reforma (Santiago, Imprenta Cervantes).

Larraguibel, Santiago (1987): Tratado de marcas comerciales (Santiago, Editorial Jurídica de Chile).

Larraguibel, Santiago (1995): Tratado sobre la Propiedad Industrial (Santiago, Editorial Jurídica ConoSur).

Lastarria, José Victorino (1856): La Constitución de la República de Chile, comentada (Valparaíso, Imprenta del Comercio).

LirA, José Bernardo (1879): La Legislación Chilena no Codificada (Santiago, Imprenta del Correo).

Mirosevic, Camilo (2007): "Origen y evolución del Derecho de Autor, con especial referencia al Derecho chileno", Revista de Derecho, Vol. XXVIII: pp. 35-82.

Montero, Arturo (1913): Registro general de patentes de invención que comprende todos los privilegios -ya sean de invención o de introducción-concedidos por el Gobierno de Chile desde 1840 hasta 1912 (Santiago de Chile, Imprenta El Globo).

Pella y Forgas, José (1892): Las Patentes de Invención y los Derechos del Inventor. Tratado de utilidad práctica para inventores e industriales (Barcelona, Administración de Industria e Invenciones).

Ruiz-Tagle, Pablo (2001): Propiedad Intelectual y Contratos (Santiago, Editorial Jurídica de Chile).

SAY, Jean Baptiste (1804): Tratado de Economía Política (Madrid, Imprenta de Pedro María Caballero).

WaLKer, Elisa (2014): Manual de Propiedad Intelectual (Santiago, Thomson Reuters).

\section{FUENTES CITADAS}

Anguita, Ricardo (1902): Leyes Promulgadas en Chile desde 1811 y hasta 1901 inclusive (Santiago, Imprenta Nacional).

Galiset, C.M. (1829): Corps du Droit Francais, Tomo I (Paris, Mahler Editeurs). 
Le Hodey, M. (1790): Journal des Etats Generaux convoqués par Louis XVI, Tomo XIX (Paris, Edición Propia).

LeTelier, Valentín (1887-1908): Sesiones de los Cuerpos Legislativos (Santiago, Imprenta Cervantes).

Novísima Recopilación de las Leyes de España (1805).

Peters, Richard (1856): The Public Statutes at Large of the United States of America, Vol. V (Boston, Little Brown \& Company). 
